\title{
Postseismic displacements following the 2007 Noto peninsula earthquake detected by dense GPS observation
}

\author{
Manabu Hashimoto ${ }^{1}$, Hiroaki Takahashi ${ }^{2}$, Ryosuke Doke $^{3}$, Minoru Kasahara $^{2}$, Akira Takeuchi $^{3}$, Kenusuke Onoue $^{1}$, \\ Yoshinobu Hoso $^{1}$, Yo Fukushima ${ }^{1}$, Kajuro Nakamura ${ }^{1}$, Fumio Ohya ${ }^{1}$, Ryo Honda $^{2}$, Masayoshi Ichiyanagi ${ }^{2}$, \\ Teruhiro Yamaguchi ${ }^{2}$, Takahiro Maeda ${ }^{2}$, and Yoshihiro Hiramatsu ${ }^{4}$ \\ ${ }^{1}$ Disaster Prevention Research Institute, Kyoto University, Gokasho, Uji, Kyoto 611-0011, Japan \\ ${ }^{2}$ Institute of Seismology and Volcanology, Graduate School, Hokkaido University, Sapporo 060-0810, Japan \\ ${ }^{3}$ Graduate School of Science and Engineering, University of Toyama, Gofuku 3190, Toyama, Toyama 930-8555, Japan \\ ${ }^{4}$ Graduate School of Natural Science and Technology, Kanazawa University, Kakuma, Kanazawa, Ishikawa 920-1192, Japan
}

(Received June 29, 2007; Revised November 3, 2007; Accepted November 13, 2007; Online published February 19, 2008)

\begin{abstract}
We have been conducting dense GPS observation in and around the epicentral region of the 2007 Noto peninsula earthquake since March 25, 2007, in order to detect postseismic displacements. Continuous observation has been underway at 12 sites to fill the gap of GEONET. Preliminary analysis of data up to early May shows that initial postseismic displacement rapidly decayed within 20 days after the occurrence of the mainshock. Horizontal displacements do not exceed $20 \mathrm{~mm}$ even at sites above the aftershock zone for this period. We also found a maximum uplift of about $20 \mathrm{~mm}$ there. Inversion of postseismic displacements with the variable slip model suggests a nearly right-lateral afterslip of less than $5 \mathrm{~cm}$ on the shallow portion of the source fault. Fitting a theoretical function to a time series of coordinate changes also suggests that the observed postseismic displacements might have been generated by afterslip.
\end{abstract}

Key words: Noto peninsula earthquake, GPS, crustal deformation, postseismic deformation, afterslip.

\section{Introduction}

On March 25, 2007, a $M_{\text {jma }}=6.9$ earthquake hit the northwestern part of the Noto peninsula, central Japan, claiming one casualty and causing serious structural damage, especially in the town of Monzen, Wajima city. This is the fourth shallow inland earthquake of $M 6.5$ or larger in the Japanese islands during the present decade.

Postseismic displacements are often observed following large earthquakes, and these convey important information on frictional properties of the source fault (e.g. Marone et al., 1991; Perfettini et al., 2004; Montesi, 2004; Miyazaki et al., 2004), viscoelastic structure in the crust and upper mantle (e.g. Thatcher et al., 1980; Pollitz, 2005), pore pressure changes (e.g. Peltzer et al., 1998; Jónsson et al., 2003), among others. These factors may also control the strain accumulation and release process associated with earthquake generation. Thus, it is essential to carry out such observations as soon as possible to reveal the detailed history of the evolution of postseismic deformations.

In Japan, the Geographical Survey Institute's Earth Observation NETwork (hereafter GEONET) is under operation and has revealed coseismic and postseismic displacements following large earthquakes (e.g. Sagiya et al., 2000; Sagiya, 2004). However, average spacing is about 20$25 \mathrm{~km}$ for GEONET, which is as large as the size of aftershock distribution of the earthquakes of $M 7$. Therefore,

Copyright (c) The Society of Geomagnetism and Earth, Planetary and Space Sciences (SGEPSS); The Seismological Society of Japan; The Volcanological Society of Japan; The Geodetic Society of Japan; The Japanese Society for Planetary Sciences; TERRAPUB a much denser network of GPS observation is required to reveal the detailed distribution of postseismic displacement following the mainshock. With this aim, we started carrying out dense continuous GPS observations in and around the epicentral region following the occurrence of the Noto peninsula earthquake.

\section{GPS Observation and Data Processing}

Aftershocks were distributed close to the northwestern coast of Noto peninsula, where only three GEONET sites are operated. Therefore, a much denser network is essential to reveal a detailed distribution of postseismic displacement. Responding to the occurrence of the Noto peninsula earthquake, three groups consisting of researchers from several universities started continuous GPS observation in and around the epicentral area. During the period from 25 to 29 March, 2007, we established 12 observation sites which are equipped with dual-frequency receivers (Fig. 1). We selected apparently stable sites, such as reinforced concrete buildings, basements of monuments etc, and fixed antenna on the roofs, because of limited time available to select sites (Fig. 2). Phase data were sampled at intervals of $30 \mathrm{~s}$, but sampling rate was higher $(0.1-1 \mathrm{~Hz})$ at some sites in order to conduct a kinematic analysis of data. For the static analysis, however, all data were decimated to 30-s sampled data with the utility TEQC (Estey and Meertens, 1999). The elevation mask was set at 5-10 .

For the analysis of GPS data, we used the Bernese software (ver. 5.0) for static positioning of daily coordinates (Hugentobler et al., 2005) with IGS final 


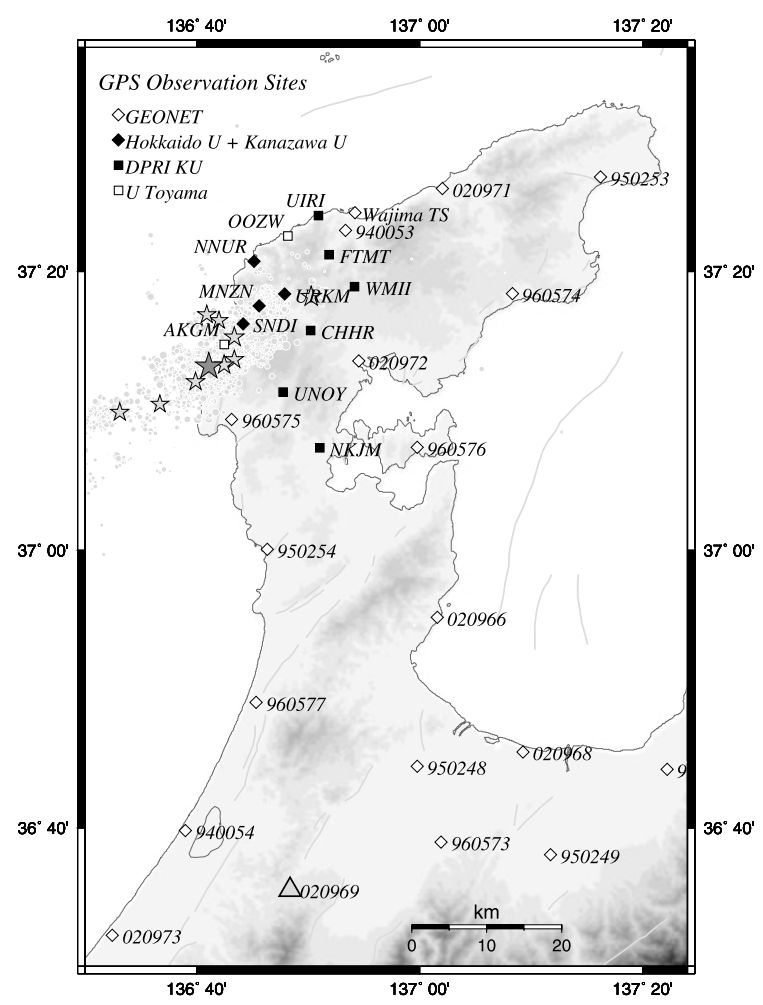

Fig. 1. Distribution of sites. Solid diamonds, solid and open squares indicate GPS sites deployed by Hokkaido University and Kanazawa University, University of Toyama, and Disaster Prevention Research Institute, Kyoto University, respectively. Open diamonds show GEONET sites. Large triangle indicates GEONET 020969, which is the reference point for displacements. Gray circles are epicenters of aftershocks determined by JMA and MRI (2007). Dark and light gray stars show the epicenter of the mainshock and epicenters of aftershocks larger than $M 4.5$, respectively. Gray lines indicate surface traces of active faults (Research Group of Active Faults of Japan, 1991).

ephemeredes, earth rotation parameters and satellite clock coefficients. All data from the IGS, GEONET and temporal sites were processed simultaneously to obtain their coordinates in ITRF2005 (http://itrf.ensg. ign.fr/ITRF_solutions/2005/ITRF2005.php). We chose remote IGS sites, such as Tsukuba (TSKB), Daejong (DAEJ), Yuzhno-Sakhalinsk (YSSK) and others, as fiducial sites and tried to strongly constrain to their predicted coordinates in ITRF2005 in order to align the site coordinates in ITRF2005. However, their preliminarily estimated coordinates sometimes largely differed from the ITRF2005 predictions. In such a case, Bernese automatically excludes such sites from the list of fiducial sites and calculates coordinates.

Time series of coordinates usually have relatively large scatters. We suspect that the scatter may be common noise that can be attributed to errors in ephemeredes and satellite clock delays and other common effects, such as troposhphere/ionosphere disturbances. In order to reduce such distubances, we fix GEONET 020969. Geographical Survey Institute (2007) (hereafter GSI) selected 020969 as the reference point for the calculation of coseismic displacements. However, we must check the stability of this site. In the calculation of time series we often apply the spatial filter technique proposed by Wdowinski et al. (1997) and Tabei and

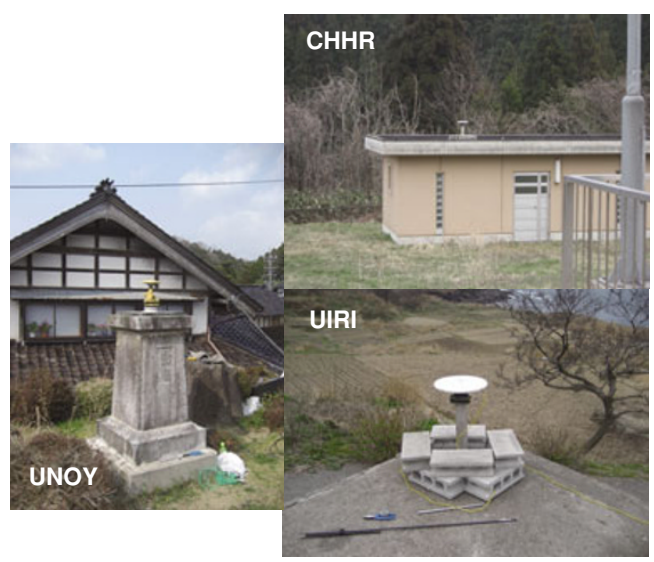

Fig. 2. Photos of representative sites: Unoya (UNOY), Chihara (CHHR) and Uiri (UIRI) sites.

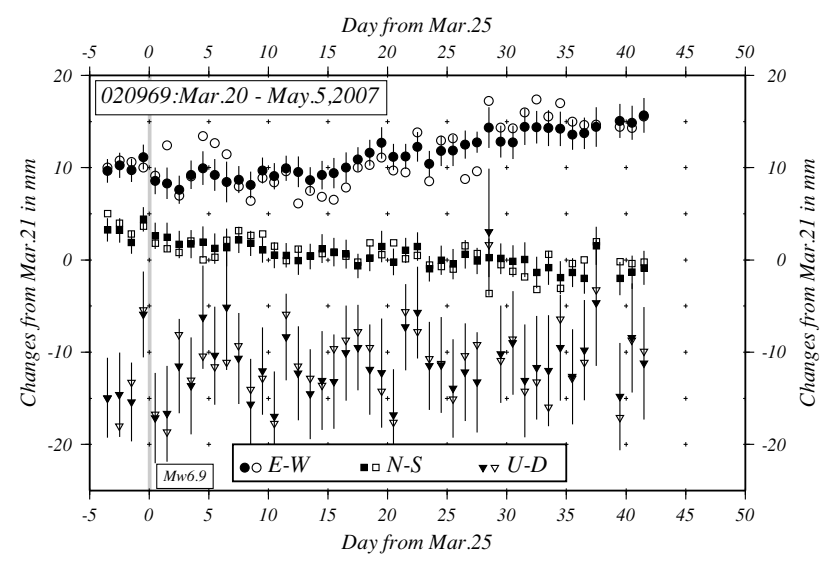

Fig. 3. Time series of changes of coordinates of GEONET site 020969 in mm since March 21, 2007, in ITRF2005. Circles, diamonds and triangles show eastward, northward and vertical components, respectively. Open and solid symbols are original and spatial-filtered data, respectively. Error bars indicate $3-\sigma$.

Amin (2002). We used the sites far away from the epicenter of the mainshock for the calculation of common mode bias. The common mode bias that was obtained was subtracted from the original time series. Figure 3 shows the observed and spatially-filtered time series of GEONET 020969 in ITRF2005. Horizontal components are rather stable, while vertical ones have as large a scatter as $10 \mathrm{~mm}$. Judging from the stability of the horizontal components and epicentral distance, the choice of GEONET 020969 as a reference site is adequate. Due to the large scatter in the vertical component, however, it is hard to discuss deformation smaller than $10 \mathrm{~mm}$.

\section{Observed Postseismic Displacement}

Figures 4-6 show the time series of coordinate changes relative to 020969. Most GEONET sites do not show any significant movements since they are located relatively far from the epicenter. However, several sites, such as 940053, 020972, AKGM, CHHR, UNOY, WMII and SNDI, show a different trend. SNDI in particular rapidly moved westward during the first 3 days and seemed to decelerate afterward. It is unfortunate that several data points are missing due to power failure and we could not know its detailed 


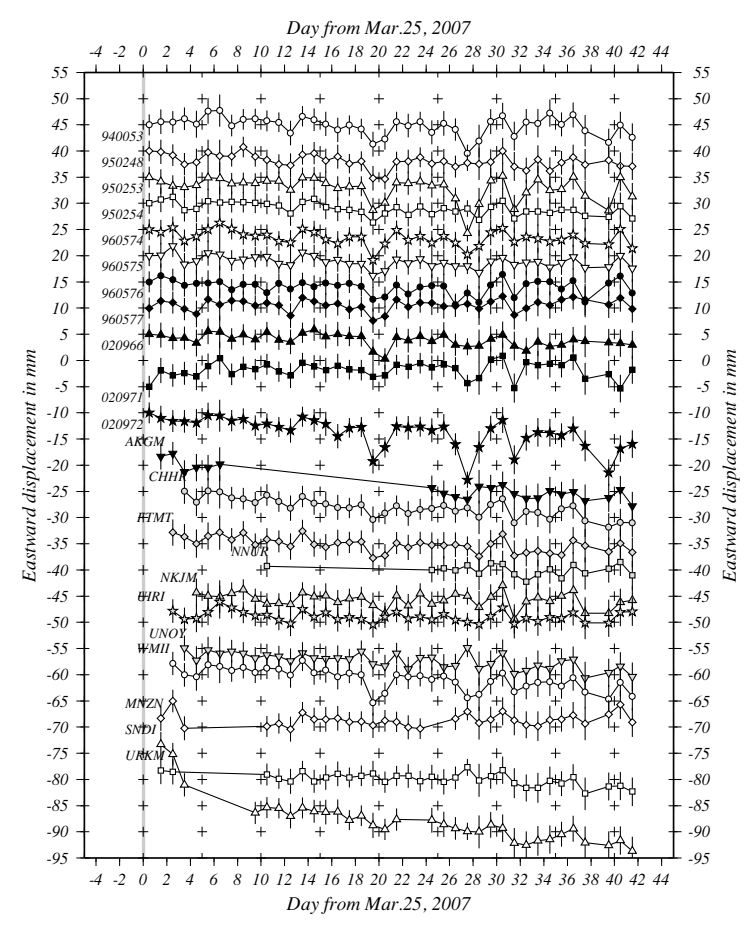

Fig. 4. Time series of changes in eastward component of coordinate of continuous GPS sites in mm since March 25, 2007. Error bars indicate $3-\sigma$.

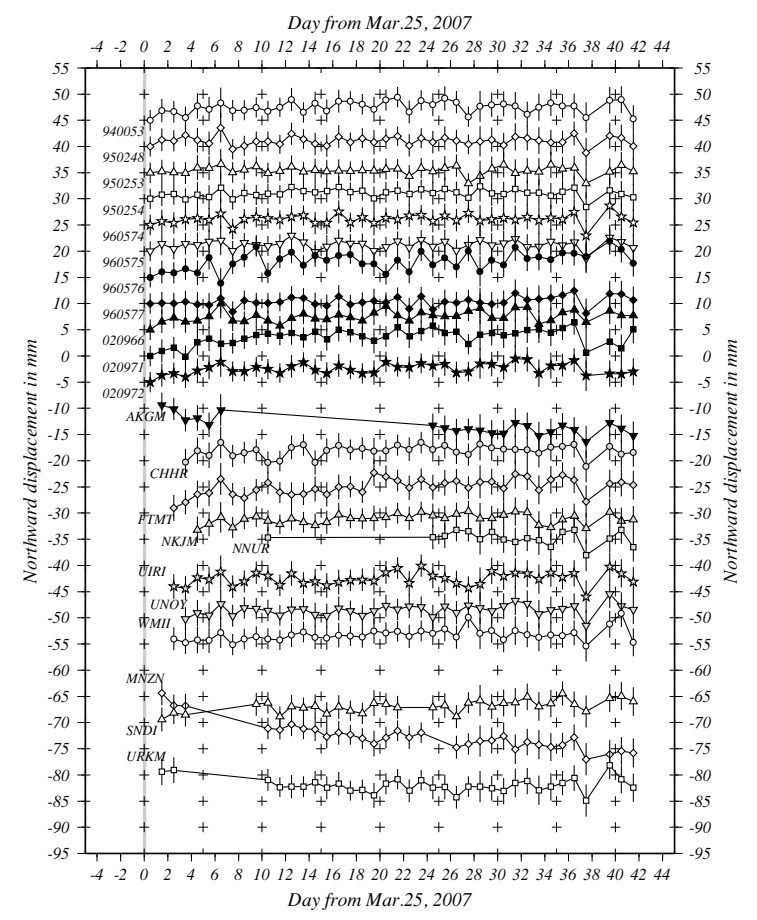

Fig. 5. Time series of changes in northward component of coordinate of continuous GPS sites in mm since March 25, 2007. See also the legend of Fig. 4.

history (Fig. 4). The total horizontal displacement did not exceed $20 \mathrm{~mm}$ by early May. AKGM and 020972 also show significant westward displacements of about $10 \mathrm{~mm}$ and $6 \mathrm{~mm}$, respectively. Spikes in the time series of the eastward component of 020972 are also recognized in other sites. Therefore, it can be interpreted as distubances, prob-

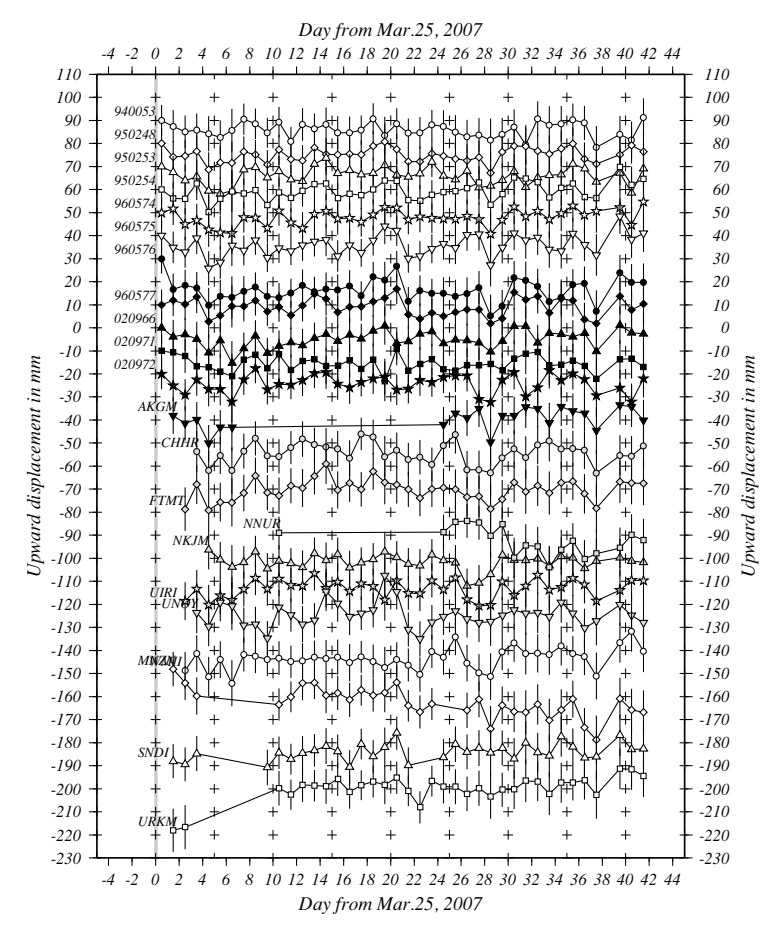

Fig. 6. Time series of changes in vertical component of coordinate of continuous GPS sites in mm since March 25, 2007. See also the legend of Fig. 4.

ably caused by local atmospheric phenomena. On the other hand, MNZN shifted southward by about $10 \mathrm{~mm}$ (Fig. 5). AKGM also has a significant southward component. Other sites moved slightly northward. With the exception of SNDI and 020972, initial rapid motions at most sites decayed during the first 20 days.

Vertical components suffered from large scatters, but some sites obviously show uplift or subsidence (Fig. 6). We observed uplift of about $10 \mathrm{~mm}$ at URKM, but MNZN, which is located about $1 \mathrm{~km}$ west of URKM, show subsidence.

Figures 7 and 8 show distribution of postseismic displacements during two different periods. Westward displacements are large near the epicenter. UIRI on the northern coast of Noto peninsula shows no significant movement. In terms of aftershock distribution, this pattern of postseismic displacements is consistent with displacements due to possible afterslip on the source fault and/or its extension. On the other hand, uplift is prevailing in and around the epicentral region, though disturbance at the reference site (020969) might affect this. A few exceptions, such as MNZN and NKJM, may have suffered from local effects possibly related to alluvial plain.

\section{Interpretation of Postseismic Displacement}

Three mechanisms are considered to be the cause of postseismic displacements: afterslip on source fault and its extension (Marone et al., 1991; Perfettini et al., 2004; Montesi, 2004), viscoelastic relaxation in the mantle (Thatcher et al., 1980; Pollitz, 2005) and poroelastic rebound (Peltzer et al., 1998; Jónsson et al., 2003). Viscoelastic relaxation usually has a time constant longer than several years. In this paper we do not consider this mechanism since we deal 


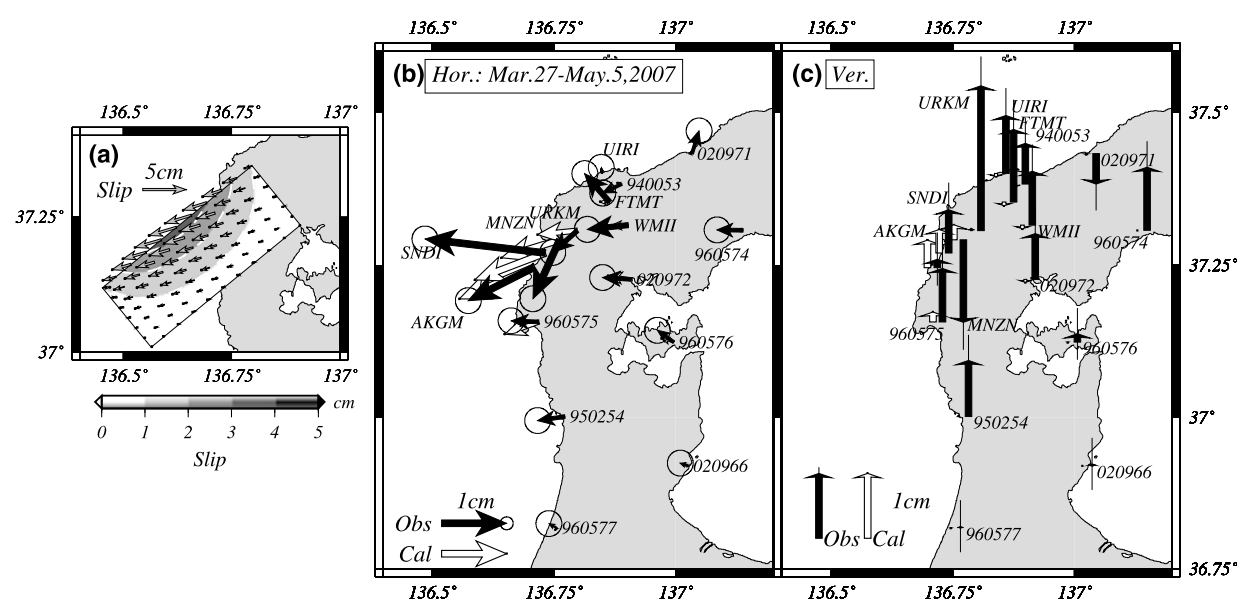

Fig. 7. Slip distribution estimated from observed displacements and horizontal and vertical postseismic displacements during the period from March 27 to May 5, 2007 relative to 020969 (GEONET Fukumitsu). (a) Estimated slip distribution. The rectangle is the fault plane on which afterslip is estimated. The fault parameters are after Fukushima et al. (2008). Arrows show estimated slip, and contours denote their magnitutde. (b) and (c) show horizontal and vertical displacements, respectively. Black and white arrows show observed and calculated displacements for optimal model shown in (a), respectively. 1- $\sigma$ error ellipses or bars are attached to observed displacements.

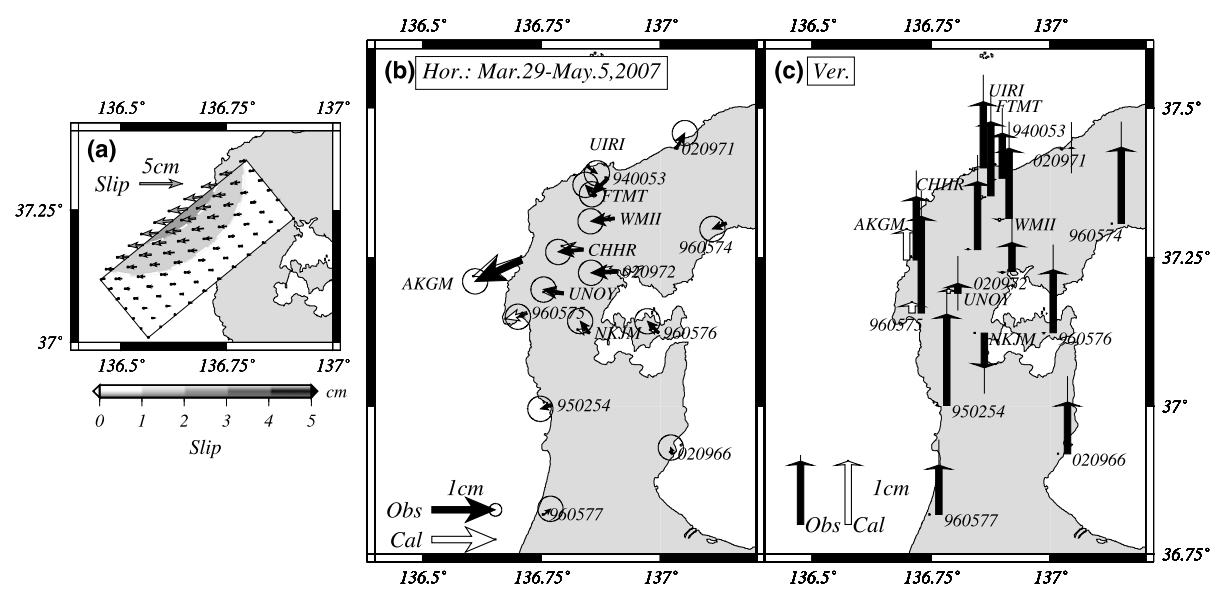

Fig. 8. Slip distribution estimated from observed displacements and horizontal and vertical postseismic displacements during the period from March 29 to May 5, 2007 with relative to 020969 (GEONET Fukumitsu). See also legend in Fig. 7.

with displacements during the first 40 days. Poroelastic rebound and afterslip are based on different mechanisms and are considered to have different spatial patterns of displacements.

We first calculated the effect of poroelastic rebound and found that measurable displacements are limited around the source fault (Fig. 9). These theoretical displacements are calculated for the GSI's (2007) model with undrained and drained Poisson's ratios of 0.31 and 0.27 , respectively, referring to Peltzer et al. (1998) and Jónsson et al. (2003). It is obvious that the theoretical postseismic displacements are not consistent with observed ones. Therefore, we discarded this mechanism.

We next performed an inversion of postseismic displacements observed during two periods (March 27-May 5, and March 29-May 5) to obtain afterslip distributions using Yabuki and Matsu'ura's (1992) scheme (Figs. 7 and 8). Fukushima et al. (2008) obtained a coseismic fault model by inverting displacements at GEONET sites and an interferogram derived from ALOS/PALSAR data. They estimated coseismic slip distribution on a fault $40 \mathrm{~km}$ in length,
$24 \mathrm{~km}$ in width that is dipping toward southeast at $48^{\circ}$. We adopted their fault and estimated afterslip distribution. During both periods we obtained afterslip on the shallow portion of the fault. The maximum slip of about $4 \mathrm{~cm}$ is found just off the coast of Noto peninsula. The estimated slips are almost right-lateral with a slight thrust component, while the thrust component is dominant for coseismic slip (Fukushima et al., 2008). These models explain horizontal displacements fairly well, but fail to explain vertical displacements especially at distant sites. Therefore, it is considered that uplift observed at distant sites is not attributed to the postseismic effect of the Noto peninsula earthquake.

In order to check if the afterslip is concordant with temporal variation, we fit a theoretical function to the time series of coordinate changes. We use the component in the direction of its maximum horizontal displacement. Due to large scatter, we do not use the vertical component. We adopted a logarithmically decaying function proposed by Marone et al. (1991):

$$
U(t)=\alpha \ln \left(\frac{\beta}{\alpha} t+1\right)+V_{p} t+U_{\text {ref }}
$$


Table 1. Statistics for the fitting of function proposed by Marone et al. (1991). $N$ is number of data. SSR represents square sum of residuals. See text for the explanation of other parameters.

\begin{tabular}{cccccrc}
\hline Site & $N$ & $\alpha(\mathrm{mm})$ & $\beta(\mathrm{mm} /$ day $)$ & $V_{p}(\mathrm{~mm} /$ year $)$ & $U_{\text {ref }}(\mathrm{mm})$ & $S S R$ \\
\hline AKGM & 23 & 2.69 & 13.46 & 8.14 & -5.83 & 27.72 \\
SNDI & 33 & 5.82 & 29.10 & -5.33 & -11.43 & 45.77 \\
MNZN & 33 & 3.09 & 15.45 & 5.72 & -6.27 & 23.66 \\
URKM & 33 & 1.89 & 2.57 & -16.77 & -2.27 & 38.06 \\
\hline
\end{tabular}

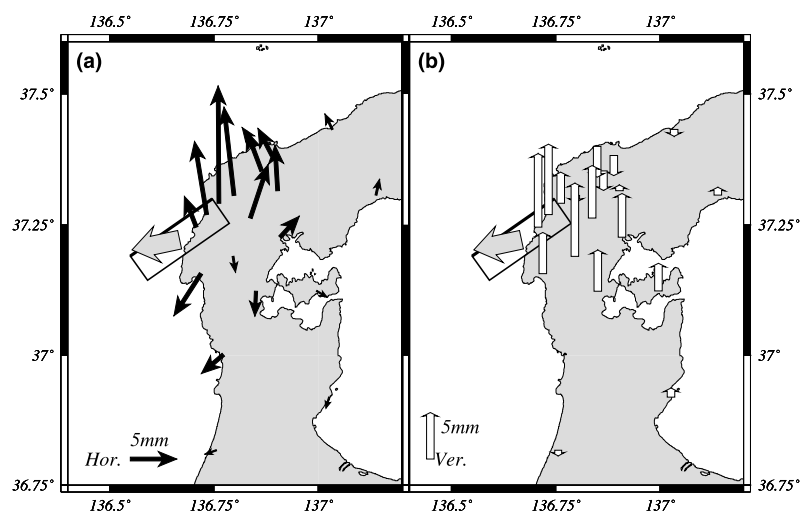

Fig. 9. Theoretical postseismic displacements for the poroelastic rebound model. Coseismic fault model is after GSI (2007). (a) and (b) show horizontal and vertical displacements, respectively. Rectangle is surface projection of the modeled fault by GSI (2007). Thick gray vector indicates coseismic slip.

where $U(t)$ is the observed horizontal dispalcement in the direction of the maximum horizontal displacement, $\alpha$ is the parameter related to $(a-b)$ in the velocity-strengthening layer, $\beta$ is related to coseismic slip velocity, $V_{p}$ is preseismic velocity and $U_{\text {ref }}$ is the offset of displacement at the start of observation. This function is based on the rate- and state-dependent friction law and aimed to represent the time evolution of the afterslip in a velocity-strengthening layer. In fitting this function to data, we performed a grid search for $\beta / \alpha$ within a range of 0.01 to 5.0 with an interval of 0.01 . As the equation is linear for $\alpha, V_{0}$ and $U_{\text {ref }}$, we applied the least square method once $\beta / \alpha$ was fixed.

Figure 10 shows the result of fitting this function to the time series of displacements at four sites (AKGM, SNDI, MNZN and URKM). Table 1 gives the statistics of fitting. This model shows a good fit to the data. Unfortunately, it is hard to discuss in detail due to missing data during the first week or two. However, the rather good fitting also supports the proposal that the observed postseismic displacements may have been caused by afterslip on a velocitystrengthening part of the source fault or its extension. Estimated $\alpha$ 's, which are related to $(a-b)$ in the velocity strengthening layer, are consistent with those for the Kobe earthquake by Kato et al. (1997). $\beta / \alpha$ 's range of 1.36-5.0, suggests very short decay time (0.2-0.74 days). Marone et al. (1991) noted that $\beta$ cannot be estimated precisely without data within a half day of the main rupture. Since the first observation included in the analysis is 1 day after the mainshock, we cannot discuss $\beta$ further. They also assumed that $V_{p}$ is one tenth or less of the long-term plate velocity in their model calculation. Our estimates of $V_{p}$ are a little larger, and negative values for SNDI and URKM were ob-

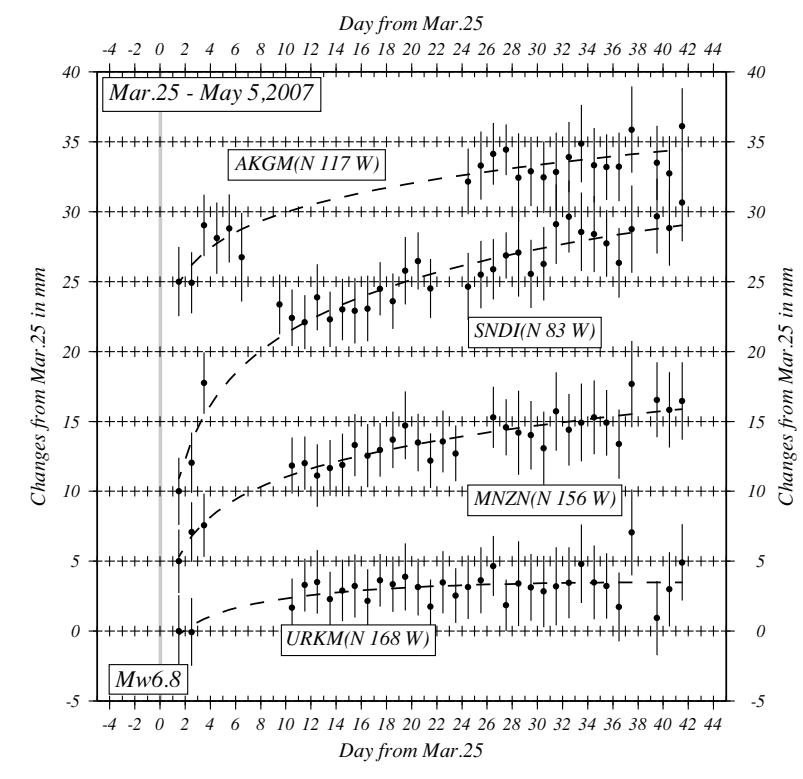

Fig. 10. Fitting of theoretical curve to the observed postseismic horizontal displacements at four sites (AKGM, SNDI, MNZN and URKM) in the direction of maximum horizontal displacements. Dashed curves indicate theoretical temporal changes based on Marone et al's (1991) formula.

tained. This issue should be discussed after data for much longer period are avaiable.

\section{Discussions and Conclusions}

Owing to the development of GPS observation technology, postseismic deformations following large inland earthquakes have been studied in detail in Japan since the 1995 Kobe earthquake (e.g. Kato et al., 1997; Nakano and Hirahara, 1997; Sagiya et al., 2002; Takahashi et al., 2005; Sagiya et al., 2005; Nakao et al., 2006). The observed postseismic displacements following these earthquakes have a tendency to decay rapidly, although the assumed mechanisms were different among these studies. Takahashi et al. (2005) and Nakao et al. (2006) used a logarithmic decaying function and obtained short decay time of 0.0310.30 days for the 2004 mid-Niigata earthquake and 223 days for the 2005 Fukuoka earthquake, respectively. Our result also gives similar characteristics, which suggests that there should be similar conditions in the crust beneath the Japanese islands.

The previous studies also proposed afterslip on source faults or their extension. Modeled faults do not reach beneath a depth of $20 \mathrm{~km}$ in their studies. Therefore, decaying time may transfer frictional properties of the velocitystrengthening layer in the upper crust. Sagiya et al. (2005) suggest a shallow afterslip for the mid-Niigata prefecture 
earthquake. Nakao et al. (2006) also obtained afterslip on the shallow portion of the source fault for the 2005 Fukuoka earthquake. We also obtained a shallow afterslip for the Noto peninsula earthquake. These studies use data from temporal sites. On the other hand, Sagiya et al. (2002) estimated the distribution of afterslip on the rather deep portion of the source fault for the 2000 Western Tottori earthquake on the basis of the analysis of GEONET data. Deformation due to the slip on the deeper part of fault can not be detected only by a dense network close to the source fault. Furthermore, frictional or viscoelastic properties are expected to be different from those in the shallower part and may yield longer time constants. Consequently, temporal observation for less than half a year can not detect a postseismic signal with much longer time constants. Continuous monitoring with a wide network such as GEONET should be conducted as long as possible.

Uplift in the northeastern Noto peninsula is hard to explain with any mechanical models. We suspect atmospheric disturbances or other non-tectonic effects may cause these signals. We also found a large variation in vertical displacements at sites near the source fault such as AKGM, SNDI, MNZN and URKM. In particular, two neighboring sites, MNZN and URKM, have opposite vertical displacements. Fukushima et al. (2008) obtained interferometric images by using ALOS/PALSAR data and showed a short wave length variation in fringes near the source fault. The above-mentioned sites are located close to these complicated fringes. It is important to check whether these sites are located exactly in fringes with a short wave length. Besides this point, the collaboration with InSAR is very important for the detection of spatial variation in threedimensional postseismic displacements.

In conclusion, our preliminary analysis of data up to early May suggests that initial postseismic displacement rapidly decayed within 20 days after the occurrence of the mainshock. We observed horizontal displacements less than $20 \mathrm{~mm}$ and a maximum uplift of about $20 \mathrm{~mm}$ even at sites above the aftershock zone for this period. The inversion with variable slip model indicates that a nearly right-lateral afterslip of less than $5 \mathrm{~cm}$ occurred on the shallow portion of the source fault. Fitting a theoretical function to the time series of horizontal coordinate changes shows the afterslip as the possible cause of observed postseismic deformation.

Acknowledgments. We would like to express sincere thankfulness to the local residents and school/government officials in Noto peninsula who kindly allowed us to make observations in their properties. We also appreciate anonymous reviewers for their comments. This work is partly supported by the Grant-in-Aid for Scientific Research "Research on aftershocks of the 2007 Noto Peninsula earthquake". We also thank the Geographical Survey Institute who kindly supplied the GEONET data. All the illustrations were prepared by Generic Mapping Tool ver. 3.3.4 by Wessel and Smith (1998).

\section{References}

Estey, L. H. and C. M. Meertens, TEQC: The Multi-Purpose Toolkit for GPS/GLONASS Data, GPS Solutions, 3, 42-49, 1999.

Fukushima, Y., T. Ozawa, and M. Hashimoto, Fault model of the 2007 Noto Hanto earthquake estimated from PALSAR radar interferometry and GPS data, Earth Planets Space, 60, this issue, 99-104, 2008.

Geographical Survey Institute, Crustal mmovements in the Hokuriku and
Chubu districts, Rep. Coord. Com. Earthq. Pred., 78, 424-456, 2007. Hugentobler, U., R. Dach, and P. Fredez, Bernese GPS Software Version 5.0, AIUB, University of Bern, $388 \mathrm{pp}, 2005$.

Japan Meteorological Agency and Meteorological Research Institute, The Noto Hanto earthquake in 2007, Rep. Coord. Com. Earthq. Pred., 78, 346-370, 2007.

Jónsson, S., P. Segall, R. Pedersen, and G. Björnsson, Post-earthquake ground movements correlated to pore-pressure transients, Nature, $\mathbf{4 2 4}$, $179-183,2003$.

Kato, T. and 29 researchers, Global positioning system observation before and after the Hyogo-ken Nanbu earthquake of January 17, 1995, Japan, J. Geod. Soc. Jpn., 43, 181-207, 1997 (in Japanese with English abstract).

Marone, C., C. H. Scholz, and R. Bilham, On the mechanics of earthquake afterslip, J. Geophys. Res., 96, 8441-8452, 1991.

Miyazaki, S., P. Segall, J. Fukuda, and T. Kato, Space-time distribution of afterslip following the 2003 Tokachi-oki earthquake: implications for variations in fault zone frictional properties, Geophys. Res. Lett., 31, L06623, doi:10.1029/2003GL019140, 2004.

Montesi, L. G., Controls of shear zone rheology and tectonic loading on postseismic creep, J. Geophys. Res., 109, B10404, doi:10. 1029/2003JB002955, 2004

Nakano, T. and K. Hirahara, GPS observations of postseismic deformation for the 1995 Hyogo-ken Nanbu earthquake, Japan, Geophys. Res. Lett., 24, 503-506, 1997.

Nakao, S., H. Takahashi et al., Postseismic deformation following the 2005 West Off Fukuoka Prefecture Earthquake (M7.0) derived by GPS observation, Earth Planets Space, 58, 1617-1620, 2006.

Peltzer, G., P. Rosen, F. Rogez, and K. Hudnut, Poroelastic deformation along the Landers 1992 earthquake surface rupture, J. Geophys. Res., 103, 30131-30145, 1998.

Perfettini, H. and J.-P. Avouac, Postseismic relaxation driven by brittle creep: a possible mechanism to reconcile geodetic measurements and the decay rate of aftershocks, application to the Chi-Chi earthquake, Taiwan, J. Geophys. Res., 109, B02304, doi:10.1029/2003JB002488, 2004

Pollitz, F. F., Transient rheology of the upper mantle beneath central Alaska inferred from the crustal velocity field following the 2002 Denali earthquake, J. Geophys. Res., 110, B08407, doi:10. 1029/2005JB003672, 2005.

Research Group of Active Faults of Japan, Active Faults in Japan: Sheet Maps and Inventories (New edition), University of Tokyo Press, Tokyo, 437 pp., 1991 (in Japanese).

Sagiya, T., A decade of GEONET: 1994-2003-The continuous GPS observation in Japan and its impact on earthquake studies-, Earth Planets Space, 56, xxix-xli, 2004.

Sagiya, T., S. Miyazaki, and T. Tada, Continuous GPS array and presentday crustal deformation of Japan, PAGEOPH, 157, 2203-2322, 2000.

Sagiya, T., T. Nishimura, Y. Hatanaka, E. Fukuyama, and W. L. Ellswroth, Crustal movements associated with the 2000 western Tottori earthquake and its fault models, ZISIN, 54, 523-534, 2002 (in Japanese with English abstract).

Sagiya, T., M. Ohzono, S. Nishiwaki, Y. Ohta, T. Yamamuro, F. Kimata, and M. Sasaki, Postseismic deformation following the 2004 mid-Niigata prefecture earthquake around the southern part of the source region, ZISIN, 58, 359-369, 2005 (in Japanese with English abstract).

Tabei, T. and W. L. Amin, Common-mode errors in the GPS coordinates time series-application of spatial filtering technique-, J. Geod. Soc. Jpn., 48, 229-241, 2002.

Takahashi, H., T. Matsushima, T. Kato, A. Takeuchi, T. Yamaguchi, Y Kohno, T. Katagi, J. Fukuda, K. Hatamoto, R. Doke, Y. Matsu'ura, and M. Kasahara, A dense GPS observation immediately after the 2004 midNiigata prefecture earthquake, Earth Planets Space, 57, 663-665, 2005.

Thatcher, W., T. Matsuda, T. Kato, and J. B. Rundle, Lithospheric loading by the 1896 Riku-u earthquake, northern Japan: Implications for plate flexure and asthenospheric rheology, J. Geophys. Res., 85, 6429-6435, 1980

Wdowinski, S., Y. Bock, J. Zhang, P. Fang, and J. Genrich, Southern California permanent GPS geodetic array: spatial filtering of daily positions for estimating coseismic and postseismic displacements induced by the 1992 Landers earthquake, J. Geophys. Res., 102, 18057-18070, 1997.

Wessel, P. and W. H. F. Smith, New, improved version of Generic Mapping Tools released, EOS Trans. Am. Geophys. U., 79(47), 579, 1998.

Yabuki, T. and M. Matsu'ura, Geodetic data inversion using a Bayesian information criterion for spatial distribution of fault slip, Geophys. $J$. Int., 109, 363-375, 1992.

M. Hashimoto (e-mail: manabu_h@mbox.kudpc.kyoto-u.ac.jp), H. Takahashi, R. Doke, M. Kasahara, A. Takeuchi, K. Onoue, Y. Hoso, Y. Fukushima, K. Nakamura, F. Ohya, R. Honda, M. Ichiyanagi, T. Yamaguchi, T. Maeda, and Y. Hiramatsu 